\title{
Anthocyanins and catechins in the berries of new strawberry cultivars grown in the conditions of the Orel region
}

\author{
Margarita Makarkina*, Sergey Knyazev, Oksana Vetrova, and Marina Zubkova \\ Russian Research Institute of Fruit Crop Breeding (VNIISPK) 302530, Zhilina, Orel district, Orel \\ region, Russian Federation
}

\begin{abstract}
The results of the study of 20 new strawberry cultivars grown in the conditions of the Central part of Russia (Orel region), according to the content of anthocyanins, catechins and the total number of polyphenols in berries, are presented. Anthocyanins and catechins are representatives of the main group of phenolic compounds, flavonoids that have a therapeutic and preventive effect on the human body. The purpose of the research is to identify the best genotypes for breeding for an improved chemical composition of berries. The determination of phenolic compounds was carried out by the photometric method. The content of anthocyanins in strawberries varied depending on the cultivar to an average degree $(\mathrm{V}=16.3 \%)$ and amounted to $51.1 \pm 1.9 \mathrm{mg} / 100 \mathrm{~g}$ with a range of variation from 40.1 to $70.2 \mathrm{mg} / 100 \mathrm{~g}$. A high content of anthocyanins $(\mathrm{mg} / 100 \mathrm{~g}$ ) was observed in Rusich (70.2), Solovushka (64.2), Darselect (62.5), Tsaritsa (59.5), Rubino civ (57.9), Sonata (55.4), Alpha (54.5), Honeoye (51.8). The average content of catechins in the berries of the studied group of cultivars also changed to an average degree $(\mathrm{V}=22.2 \%)$ from 71.4 to $174.6 \mathrm{mg} / 100 \mathrm{~g}$ with an average $\mathrm{c}$ value of $124.9 \pm 6.2 \mathrm{mg} / 100 \mathrm{~g}$. The high content of catechins in berries was found in Rusich $(136,2)$, Clery $(132,0)$, Rubino civ $(137,4)$, Sara $(137,7)$, Vima Kimberly $(139,5)$, Dezy $(152,5)$, Sonata $(164,9)$, Solovushka $(168,2)$ and Alpha $(174,6)$. There was no correlation between the accumulation of anthocyanins and catechins in strawberries $(\mathrm{r}=+0.149)$. According to the total number of polyphenols (more than $500 \mathrm{mg} / 100 \mathrm{~g}$ ) in the berries, Alpha, Rusich, Solovushka, Dezy and Rubino civ are distinguished.
\end{abstract}

\section{Introduction}

The improvement of life quality is impossible without proper nutrition. At present time, the state policy of the Russian Federation, reflected in the Decree of the Government of the Russian Federation No. 1364-r dated June 29, 2016 "On approval of the Strategy for improving the quality of food products until 2030", pays great attention to the of the population with high-quality food products, including a sufficient number of fruits and

\footnotetext{
*Corresponding author: makarkina@vniispk.ru
} 
berries in the diet containing biochemical substances that are inherent only provision in them.

The lack of fruits and berries in the diet leads to nutritional imbalance, provoking an excess of weight and causing a number of pathologies in the population, such as neurodegenerative disorders, metabolic changes, cardiovascular and oncological diseases $[1,2]$. The nutritional value of fruits and berries is due to the presence in their composition of vital nutrients and biologically active substances necessary for the human body. Common strawberry (Fragaria x ananassa Duch.) is no exception.

Common garden strawberry is loved by the population for its unique taste and aroma, which explains its demand $[3,4]$. The composition of its berries includes easily digestible sugars, organic acids, ascorbic acid, phenolic (P-active) compounds, etc., which have an undeniably beneficial effect on the human body, have high physiological activity [5-10] and are part of the Mediterranean diet [11]. The consumption of strawberries significantly improves the overall antioxidant status of human blood [1].

Phenolic compounds with P-vitamin activity are of particular value among the biologically active substances of common garden strawberry. Being a strong antioxidant, phenolic compounds, absorbing the active forms of oxygen and nitrogen, in combination with other vitamins (to a greater extent with ascorbic acid), have a beneficial effect on the hematopoietic system of the human body, reduce the risk of cardiovascular and other diseases $[12,7]$. There are data indicating the importance of phenolic compounds as signaling particles involved in the modulation of signaling pathways and affecting gene expression, in addition to the effect in the digestive system [13, 6]. Flavonoids have the greatest physiological activity [14-16,9], namely anthocyanins and catechins.

Anthocyanins are water-soluble non-plastid, unlike chlorophyll, plant pigments, which are glycosides of anthocyanidins by chemical composition, characterized by a basic structure of $\mathrm{C}_{6}-\mathrm{C}_{3}-\mathrm{C}_{6}$, coloring fruits and flowers in red, blue and purple colors. This valuable property allows them to be used as natural dyes in the food industry $[17,6,18]$. Exactly the natural dyes of these colors that contribute to the reduction of oncological diseases, improve memory and normal aging [19].

Strawberry berries contain glycosides of pelargonidin and cyanidin. The concentration and qualitative composition of strawberry anthocyanins determine both the sensory qualities (appearance) and the biological value of fresh berries and products from them [6]. Catechins are a polyphenolic antioxidant flavan-3-ol, which is a colorless compound, tasteless or with a slight astringent taste. Catechins exhibit antitumor, antimutagenic, cardioprotective effect, contribute to blocking the development of neurodegenerative diseases (Alzheimer disease) [19-22].

Based on the above, there is no doubt about the strawberry value. Nevertheless, a special priority belongs to the genotype, i.e. the genetic origin of the cultivated cultivars $[4,18,23-$ 26]. For the Russian Research Institute of Fruit Crop Breeding (VNIISPK), new genotypes are of undoubted interest as sources of various traits, including biochemical ones, for use in breeding programs. The purpose of our research was to study new cultivars of strawberry in the VNIISPK gene pool according to the content of the main phenolic components in their berries and to identify the best genotypes for breeding for an improved chemical composition of berries.

\section{Materials and methods}

The objects of the research were 20 new cultivars of common garden strawberry grown at the collection site of VNIISPK. Sampling was carried out in the berry picking maturity stage in the second collection. Biochemical studies were carried out in the laboratory of biochemical and technological assessment of cultivars and storage of VNIISPK. The total 
amount of anthocyanins, catechins and polyphenols in berries was determined by photometric method using a FEC CFC photometer-3-01-"ZOMZ" ["Program and methodology of cultivar study of fruit, berry and nut crops" (Orel, 1999)]. The obtained samples, taken in two repetitions, were fixed with $96 \%$ ethyl alcohol, which were stored for one month, and then extracted with ethyl alcohol. The method for determining anthocyanins was based on the reaction of anthocyanins with acid $96 \%$ ethyl alcohol, the control was $75 \%$ ethyl alcohol; the method for determining catechins was based on the reaction of berry catechins with a vanillin reagent (vanillin dissolved in concentrated hydrochloric acid). The total number of polyphenols was determined by the method using the Folin-Denis reagent. The variation coefficients (V\%) were calculated considering threeyear data.

Statistical processing of the research results was carried out using the analysis package of the Microsoft Excel and STATISTICA 6.0 programs.

\section{Results and discussion}

The three-year study showed that the average content of total number of anthocyanin compounds in the berries for the group of the studied strawberry cultivars was changed to a medium degree, as evidenced by the variation coefficient (V\%), equal to $16.3 \%$, not exceeding $20,0 \%$, and was $51.1 \pm 1.9 \mathrm{mg} / 100 \mathrm{~g}$, with a range of variation from 40,1 (Jonsok) to $70.2 \mathrm{mg} / 100 \mathrm{~g}$ (Rusich). In the control cultivar Rubinovy Kulon, this indicator was at the level of the average cultivar value (Table 1).

Table 1. The content of anthocyanins (mg/100 g) in strawberries (2017-2019).

\begin{tabular}{|l|c|c|c|}
\hline \multicolumn{1}{|c|}{ Variety name } & $\begin{array}{c}\text { Average, } \\
\overline{\mathrm{x}} \pm \mathrm{m}\end{array}$ & Limits of diversity & $\begin{array}{c}\text { Variation } \\
\text { coefficient, V\% }\end{array}$ \\
\hline Alpha & $54.5 \pm 16.7$ & $35.4-87.8$ & 53.1 \\
\hline Bereginya & $50.4 \pm 15.5$ & $24.6-95.3$ & 61.4 \\
\hline Rosinka & $42.0 \pm 6.9$ & $31.8-55.8$ & 33.1 \\
\hline Rubinovy Kulon (c.) & $48.3 \pm 4.8$ & $41.2-57.4$ & 17.2 \\
\hline Rusich & $70.2 \pm 16.6$ & $41.4-98.9$ & 41.0 \\
\hline Solovushka & $64.2 \pm 4.9$ & $55.2-78.0$ & 9.7 \\
\hline Urozhaynaya CGL & $46.4 \pm 3.1$ & $37.2-53.8$ & 15.1 \\
\hline Tsaritsa & $59.5 \pm 11.4$ & $36.6-71.2$ & 33.3 \\
\hline Clery & $43.2 \pm 2.4$ & $37.8-46.5$ & 11.1 \\
\hline Darselect & $62.5 \pm 15.2$ & $43.2-92.5$ & 42.1 \\
\hline Dezy & $41.8 \pm 9.6$ & $26.4-59.4$ & 39.7 \\
\hline Vima Kimberly & $45.8 \pm 4.1$ & $41.4-54.0$ & 15.5 \\
\hline Vima Zanta & $51.0 \pm 7.3$ & $40.2-72.0$ & 28.4 \\
\hline Honeoye & $51.8 \pm 1.4$ & $49.8-54.6$ & 4.8 \\
\hline Jonsok & $40.1 \pm 15.4$ & $25.2-92.5$ & 65.6 \\
\hline Marmolada & $46.2 \pm 8.7$ & $30.6-60.6$ & 32.6 \\
\hline Rubino civ & $57.9 \pm 3.4$ & $51.9-63.6$ & 10.1 \\
\hline Sara & $47.0 \pm 4.3$ & $39.0-57.6$ & 18.5 \\
\hline Sonata & $55.4 \pm 10.7$ & $40.8-76.2$ & 33.0 \\
\hline NF 311 (Alba) & $44.1 \pm 6.5$ & $35.4-56.7$ & 25.3 \\
\hline Average for variety, $\overline{\mathrm{x}} \pm \mathrm{m}$ & $\mathbf{5 1 . 1 \pm 1 . 9}$ & - & - \\
\hline Minimum & $\mathbf{4 0 . 1}$ & $\mathbf{2 4 . 6}$ & $\mathbf{4 . 8}$ \\
\hline Maximum & $\mathbf{7 0 . 2}$ & $\mathbf{9 8 . 6}$ & $\mathbf{6 5 . 6}$ \\
\hline $\begin{array}{l}\text { Degree of } \\
\text { variability (V,\%) }\end{array}$ & $\mathbf{1 6 . 3}$ & - & - \\
\hline
\end{tabular}


In Rusich (70.2), Solovushka (64.2), Darselect (62.5), Tsasritsa (59.5), Rubino civ (57.9), Sonata (55.4), Alpha (54.5), Honeoye (51.8) a content of anthocyanins (mg/100 g) higher than the average cultivar value was observed. Honeyoye, Solovushka and Rubino civ reacted the least to changes in the conditions of the growing season, the variation coefficients were $4.8,9.7$ and $10.1 \%$, respectively, and indicated the stability of the studied biochemical trait. These two indicators characterize the breeding value of these cultivars. Despite the high variability of the trait, high accumulation of anthocyanins in some years was observed in several cultivars, more than $80.0 \mathrm{mg} / 100 \mathrm{~g}$ : Alpha $(87,8 \mathrm{mg} / 100 \mathrm{~g})$, Bereginya (of $95.8 \mathrm{mg} / 100 \mathrm{~g}$ ), Rusich $(98,9 \mathrm{mg} / 100 \mathrm{~g}$ ), Darselect $(92,5)$, Jonsok $(92,5$ $\mathrm{mg} / 100 \mathrm{~g}$ ). These cultivars can also be used as parental forms in breeding programs, since positive transgressions may occur in their hybrid offspring.

The average content of catechins in the berries of the studied group of cultivars changed to an average degree ( $\mathrm{V}=22.2 \%$ ) from 71.4 (Tsaritsa) to $174.6 \mathrm{mg} / 100 \mathrm{~g}$ (Alpha) with an average cultivar value of $124.9 \pm 6.2 \mathrm{mg} / 100 \mathrm{~g}$ (Table 2 ). The high content of catechins in fruits (more than 130,0 mg/100 g) was noted in Rusich $(136,2)$, Clery $(132,0)$, Rubino civ $(137,4)$, Sara $(137,7)$, Vima Kimberly $(139,5)$, Dezy $(152,5)$, Sonata $(164,9)$, Nightingale $(168,2)$ and Alpha $(174,6)$. The variability of the trait in the isolated cultivars Alpha and Clery was expressed to an average degree, the variation coefficients were 17.3 and $11.5 \%$, respectively. In Rusich, Solovushka, Dezy, Sara, Sonata, and Vima Kimberly, despite the high trait plasticity (variation coefficients above 30.0\%), in some years the content of catechins in berries was higher than $190.0 \mathrm{mg} / 100 \mathrm{~g}$. The control cultivar Rubinovy Kulon accumulated catechins from 64.0 to $116.0 \mathrm{mg} / 100 \mathrm{~g}$ - below the average cultivar value.

Table 2. Catechin content (mg/100 g) in strawberries (2017-2019).

\begin{tabular}{|l|c|c|c|}
\hline \multicolumn{1}{|c|}{ Variety name } & $\begin{array}{c}\text { Average, } \\
\overline{\mathrm{x}} \pm \mathrm{m}\end{array}$ & Limits of diversity & $\begin{array}{c}\text { Variation } \\
\text { coefficient, V\% }\end{array}$ \\
\hline Alpha & $174.6 \pm 17.4$ & $140.0-195.8$ & 17.3 \\
\hline Bereginya & $119.2 \pm 12.1$ & $86.8-145.0$ & 20.3 \\
\hline Rosinka & $99.0 \pm 14.1$ & $66.0-135.0$ & 28.4 \\
\hline Rubinovy Kulon (c.) & $96.0 \pm 16.0$ & $64.4-116.0$ & 28.8 \\
\hline Rusich & $136.2 \pm 52.7$ & $41.9-224.0$ & 67.0 \\
\hline Solovushka & $168.2 \pm 37.0$ & $102.4-267.5$ & 44.0 \\
\hline Urozhaynaya CGL & $109.6 \pm 15.8$ & $95.6-156.8$ & 28.8 \\
\hline Tsaritsa & $71.4 \pm 12.3$ & $48.0-89.6$ & 29.8 \\
\hline Clery & $132.0 \pm 7.6$ & $119.5-150.8$ & 11.5 \\
\hline Darselect & $129.9 \pm 8.7$ & $120.0-147.2$ & 11.6 \\
\hline Dezy & $152.5 \pm 49.7$ & $102.4-251.4$ & 56.2 \\
\hline Vima Kimberly & $139.5 \pm 27.3$ & $108.5-194.0$ & 33.9 \\
\hline Vima Zanta & $121.2 \pm 5.6$ & $108.8-136.0$ & 9.2 \\
\hline Honeoye & $96.7 \pm 28.4$ & $45.0-142.8$ & 50.8 \\
\hline Jonsok & $104.7 \pm 15.5$ & $76.0-160.7$ & 33.1 \\
\hline Marmolada & $88.3 \pm 16.4$ & $59.4-116.0$ & 32.1 \\
\hline Rubino civ & $137.4 \pm 20.6$ & $103.5-174.6$ & 26.0 \\
\hline Sara & $137.7 \pm 29.2$ & $94.1-218.4$ & 43.4 \\
\hline Sonata & $164.9 \pm 27.8$ & $83.2-202.5$ & 33.7 \\
\hline NF 311 (Alba) & $107.6 \pm 16.3$ & $68.0-147.2$ & 30.3 \\
\hline Average for variety, $\overline{\mathrm{x}} \pm \mathrm{m}$ & $\mathbf{1 2 4 . 9} \pm \mathbf{6 . 2}$ & $\mathbf{2 4 . 6 - 9 8 . 9}$ & - \\
\hline Minimum & $\mathbf{7 1 . 4}$ & $\mathbf{4 1 . 9}$ & \\
\hline Maximum & $\mathbf{1 7 4 . 6}$ & $\mathbf{2 6 7 . 5}$ & \\
\hline $\begin{array}{l}\text { Degree of } \\
\text { variability (V, \%) }\end{array}$ & $\mathbf{2 2 . 2}$ & - & - \\
\hline & & & \\
\hline
\end{tabular}


To determine whether there was a correlation between the two studied biochemical traits, we calculated the correlation coefficient (r). Its value was equal to +0.149 , indicating that there was no relation between the accumulation of anthocyanins and catechins in strawberries. Despite the absence of such a relation, Alpha, Rusich, Solovushka, Rubino civ, Sonata and Honeoye had a high content of both anthocyanins and catechins in berries.

The total content of polyphenolic substances was determined in the berries of the studied group of strawberry cultivars. The average content was $415.0 \pm 17.1 \mathrm{mg} / 100 \mathrm{~g}$ with an average variation from 286.1 (Rosinka) to $517.3 \mathrm{mg} / 100 \mathrm{~g}$ (Rubino civ), the variation coefficient was $18.5 \%$. All of the cultivars were distributed according to the amount of accumulated phenolic substances into three groups (Table 3).

Table 3. Distribution of strawberry cultivars by the content of polyphenolic substances (2017-2019).

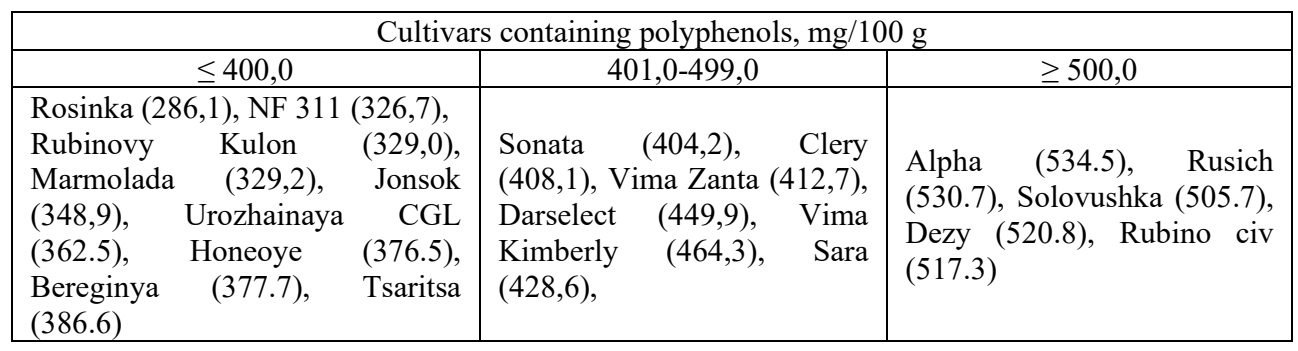

Most of the cultivars (45\%) were included in the group with accumulation of polyphenols of $400.0 \mathrm{mg} / 100 \mathrm{~g}$ or less, in the other two groups the varieties were distributed approximately equally. The maximum accumulation of polyphenols in berries (500.0 $\mathrm{mg} / 100 \mathrm{~g}$ or more) was observed in strawberry varieties Alpha, Rusich, Solovushka, Dezy, Rubino civ. The control cultivar Rubinovy Kulon was included in the first group $(\leq 400.0$ $\mathrm{mg} / 100 \mathrm{~g})$.

\section{Conclusions}

As a result of the conducted studies of the content of phenolic compounds - anthocyanins and catechins in the berries of 20 new strawberry cultivars grown in the conditions of the Central part of Russia (Orel region), the cultivars were identified for each studied trait that are of interest for use in breeding programs, including the improvement the chemical composition of fruits. Rusich, Solovushka, Darselect, Tsaritsa, Rubino civ, Sonata, Alpha, Honeoye; were identified for the accumulation of anthocyanins; Rusich, Clery, Rubino civ, Sara, Vima Kimberly, Dezy, Sonata, Solovushka and Alpha for catechins. Alpha, Rusich, Solovushka, Rubino civ, Sonata and Honeoye had a high content of both components. The maximum accumulation of polyphenols in berries $(500.0 \mathrm{mg} / 100 \mathrm{~g}$ or more) was observed in strawberry cultivars Alpha, Rusich, Solovushka, Dezy and Rubino civ. Alpha, Rusich and Rubino civ are complex sources of phenolic compounds. $\mathrm{T}$

\section{References}

1. S. Tulipani, T. Armeni, F. Giampieri, J.M. Alvarez-Suarez, A. M. Gonzalez-Paramas, C. Santos-Buelga, F. Busco, G. Principato, S. Bompadre, J. L. Quiles, B. Mezzetti, M. Battino, Food Chemistri, 156 (1), 87-93 (2014) https://doi.org/10.1016/j.f oodchem.2014.01.098 
2. A. Cassidy, V. Bertoia, S. Chiuve, A. Flint, J. Forman, E.B. Rimm, The American Journal of Clinical Nutrition, 104 (3), 587-594 (2016) https://doi.org/10.3945/ ajcn.116.133132

3. S.D. Aitzhanova, Modern varieties and technologies for intensive gardens: materials of the international scientific and practical conference, Orel: VNIISPK, 11-13 (2013)

4. I.V. Lukyanchuk, Fruit and berry growing in Russia, 39, 127-130 (2014)

5. A. Cassidy, E.J. O’Reilly, C. Kay, L. Sampson, M. Franz, J.P. Forman, G. Curhan, E.B. Rimm, The American Journal of Clinical Nutrition, 93 (2), 338-347 (2011) https://doi.org/10.3945/ajen.110.006783

6. K. Aabu, S. Mazur, A. Nes, G. Skrede, Food Chemistry, 132, 86-97 (2012) https://doi.org/10.1016/j.foodchem.2011.10.037

7. S. Afrin, M. Gasparrini, T.Y. Forbes-Hernandes, P. Reboredo-Rodriquez, B. Mezzetti, A. Varela-López, F. Giampieri, M. Battino, J. Agric. Food Chem, 64 (22), 4435-4449 (2016) https://doi.org/10.1021/acs.jafc.6b00857

8. M.Yu. Akimov, I.V. Lukyanchuk, E.V. Zhbanova, A.S. Lyzhin, Chemistry of vegetable raw materials, 1, 5-18 (2020) 10.14258/jcprm. 2020015511

9. M.Yu. Akimov, E.V. Zhbanova, V.N. Makarov, I.B. Perova, L.V. Shevyakova, O.A. Vrzhesinskaya, N.A. Beketova, O.V. Kosheleva, M.N. Bogarchuk, E.V. Rylina, I.V. Lukyanchuk, A.M. Mironov, Nutrition issues, 88 (2), 64-72 (2019) 10.24411/00428833-2019-10019

10. I.M. Kulikov, S.D. Aitzhanova, N.V. Andronova, A.A. Borisova, T.A. Tumaeva, Horticulture and Viticulture, 3, 5-10 (2020) 10.31676/0235-2591-2020-3-5-10

11. F. Giampieri, S. Tulipani, Alvarez-Suarez J.M., J.L. Quiles, B. Mezzetti, M. Battino, J. Nutrition, 28 (1), 9-19 (2012) https://doi.org/10.1016/j.nut.2011.08.009

12. I. Ignat, I. Volf, V.I. Popa, Food Chemistry, 126 (4), 1821-1835 (2011) .https://doi.org/10.1016/j.foodchem.2010.12.026

13. M. Battino, J. Beekerwilder, B. Denoyes-Rothan, M. Laimer, G.J. McDougall, B. Mezzetti, Nutrition Reviews, 67 (1), S145-S150 (2009) https://doi.org/10.1111/j.17534887.2009.00178.x

14. R.H. Liu, J. Food Sci., 78 (sl), 18-25 (2013) https://doi.org/10.1111/1750-3841.12101

15. A. Rodriguez-Mateos, D. Vauzour, C.G. Krueger, D. Shanmuganayagam, J. Reed, L. Calani, P. Mena, D. Del Rio, A. Crozier, Arch Toxicol, 88(10), 1803-1853 (2014) http://dx.doi.org/10.1007/s00204-014-1330-7

16. Y. Aguilera, M.A. Martin-Cabrejas, E. González de Mejia, Phytochem Rev. 15 (3), 405-423. (2016) https://doi.org/10.1007/s11101-015-9443-z

17. A.M. Makarevich, A.G. Shutova, E.V. Spiridovich, V.N. Reshetnikov, Proceedings of the Belarusian State University. Ser. Physiological, biochemical and molecular bases $\begin{array}{llllll}\text { of functioning of biosystems, } 4 & \text { (2), } & 147-157 & \text { (2009) }\end{array}$ http://elib.bsu.by/handle/123456789/16261

18. I.V. Lukyanchuk, E.V. Zhbanova, Bulletin of the Tomsk State University, Biology, (38), 134-148 (2017) 10.17223/19988591/38/8

19. S.H. Nile, S.W. Park, Nutrition, $30 \quad$ (2), 134-144 (2014) https://doi.org/10.1016/j.nut.2013.04.007

20. I.C.W. Arts, B. van de Putte, P.C.H. Hollman, Error! Hyperlink reference not valid.J. Agric. Food Chem, 48 (5), 1746-1751 (2000) https://doi.org/10.1021/jf000025h 
21. C. Auger, N. Al-Awwadi, A. Bornet, J.M. Rouanet, F. Gasc, G. Cros, P.L. Teissedre, $\begin{array}{lllll}\text { Food Research International, } 37 \quad 3), \quad 233-245 & \text { (2004) }\end{array}$ https://doi.org/10.1016/j.foodres.2003.11.008

22. M. Isemura, Molecules, 24 (3), 528. (2019) https://doi.org/10.3390/molecules2 4030528

23. K. Gündüz, E. Özdemir, Food Chemistry, 155 (15), 298-303 (2014) https://doi.org/10.1016/j.foodchem.2014.01.064

24. M.A. Makarkina, A.R. Pavel, Modern gardening - Contemporary horticulture, 2, 10-16 (2017) 10.24411/2218-5275-2017-00021

25. O.A. Gorelikova, T.G. Prichko, Scientific works of SKFNTSSVV, 14, 15-163 (2018) 10.30679/2587-9847-2018-14-159-163

26. T.G. Prichko, M.G. Germanova, T.L. Smelik, Fruit growing and viticulture in the South of Russia, 58 (04), 104-113 (2019) 10.30679/2219-5335-2019-4-58-104-113 